This is a self-archived version of an original article. This version may differ from the original in pagination and typographic details.

Author(s): Salminen, Timo; Marttunen, Miika; Laurinen, Leena

Title: Visualising knowledge from chat debates in argument diagrams

Year: 2010

Version: Accepted version (Final draft)

Copyright: @ 2010 Blackwell Publishing Ltd

Rights: In Copyright

Rights url: http://rightsstatements.org/page/InC/1.0/?language=en

Please cite the original version:

Salminen, T., Marttunen, M., \& Laurinen, L. (2010). Visualising knowledge from chat debates in argument diagrams. Journal of Computer Assisted Learning, 26(5), 379-391.

https://doi.org/10.1111/j.1365-2729.2010.00354.x 


\title{
Visualising knowledge from chat debates in argument
}

\section{diagrams}

\author{
Abstract \\ This study investigates whether combining chat discussion and construction of an \\ argument diagram stimulates students to formulate new ideas in practising \\ argumentation. In this study 16 secondary school students discussed vivisection and \\ gender equality in pairs using both free and structured chat tools. In structured chat the \\ students selected and completed partial sentences provided by the computer. After the \\ discussion they jointly constructed either argument diagrams freely based on the \\ previous discussions with an Internet tool or modified a diagram the computer had \\ constructed automatically during the structured chat. The freely constructed diagrams \\ contained more of the students' prior knowledge than the modified diagrams. However, \\ the different types of diagrams did not differ significantly in breadth, depth, or balance \\ of argumentation. Thus, free construction of argument diagrams seems to activate \\ students to incorporate their prior knowledge into those diagrams.
}

Keywords: collaborative argumentation, visualisation of argumentation, argument diagram, computer chat, secondary education

\section{Introduction}

Skills in evaluating, constructing and transforming knowledge not only by ourselves alone but also together with others are highly valued in today's network society. These skills are essential not only for learning across the lifespan and in many careers involving non-routine interactive work, but also for participating in general debates on 
many societal questions. Participation in debates entails the ability to express thoughts and ideas in a clear and convincing way, as well as constructively to consider and judge others' views and arguments. However, it has been shown that both adolescents (e.g. Chan 2001; Marttunen et al. 2005) and university students (Marttunen 1997) have difficulties in acquiring argumentation skills. These skills can be practised through faceto-face interaction or in computer-assisted learning environments by using graphical or other non-verbal techniques for visualising argumentation (van Gelder 2003). When argumentation is visualised, chains of reasoning, conclusions, and logical relationships between arguments are made explicit. It is assumed that such explicitness helps students to deepen their argumentation and better understand the subject matter.

In this study, secondary school students constructed argument diagrams in pairs on the basis of chat debates. The aim was to clarify whether combining these two modes of representations (chat and diagram) in practising argumentation enables students to deepen and broaden their arguments.

\section{Collaborative argumentation}

Argumentation through dialogue has been seen as one prerequisite for successful collaborative learning (e.g. Mercer 1996). The term collaborative argumentation has been used to refer to a method of collaborative learning in which the participants strive towards the common goal of attaining a better understanding of the issues in question by putting forward different points of view, claims and arguments, and by exploring them in a deep and critical way (Litosseliti et al. 2005).

Earlier empirical studies have shown collaborative argumentation to have positive learning effects in terms of improving reasoning about a topic (Kuhn et al. 1997), solving problems (Erkens 1997) and writing argumentative and persuasive essays 
(Reznitskaya et al. 2001). However, such effects are not usually achieved without scaffolding. It is possible to scaffold argumentative co-elaboration of knowledge (Baker 2003) by structuring learning tasks and student interaction in computer supported collaborative learning environments. In this study, synchronous computer-based communication and visualisation tools were used to support students' joint construction of argumentative knowledge.

\section{Argumentation through free and structured chat}

Synchronous chat interaction has many advantages in enhancing learning and argumentation skills. Condon and Cech (1996) have stated that the need for brevity during chat interaction may cause students to articulate their opinions and arguments more precisely, thereby clarifying their thinking. Morgan and Beaumont (2003), in turn, found that chat interaction helped students to express more substantial, sound, and logical arguments, and to offer examples and justifications more sharply to the point. Furthermore, in the experimental studies by Veerman (2000) synchronous computermediated communication contained more counterargumentative speech acts than asynchronous communication.

One problem of synchronous chat interaction is that it suffers from a lack of focus and coherence due to the lack of non-verbal communication (Burnett 2003). On the other hand, the lack of non-verbal communication can also benefit learning due to the need, when communication is based on written text only, for the participants to communicate in a clear and explicit way, and check whether they understand each other (Erkens 2004). Another problem with chat is that participants can compose and send messages or reply to previous messages in parallel, resulting in multi-stranded and dispersed discussions. Dispersion of discussion together with the pressure to reply 
quickly to others' opinions makes it difficult to explore ideas in any depth or to explain the argumentative relations between claims, reasons and justifications (Burnett 2003). Weger and Aakhus (2003), for example, found that in chat interaction arguments tended to be underdeveloped or unresponsive to those raised by other participants.

The problems of lack of focus and coherence as well as dispersed discussion may be eased through structuring a discussion by using prompts, such as questions or rules for discussion. Hron et al. (2000) state that the use of prompts can help to maintain focus on the subject matter, decrease off-task talk, and lead to a more coherent discussion on the topic. In addition, Baker and Lund (1997) found that students' structured interaction was more reflective than their unstructured communication. Furthermore, McAlister (2004) used the AcademicTalk tool with sentence openers (such as "Can you give an example...?", "I disagree because...", or "Let me elaborate...") and found that students addressed previous arguments more clearly, and both examined and challenged more arguments compared with students using free chat. However, students do not always use such sentence openers in the intended way (Robertson et al. 1998). Instead, students tend to use the most generic sentence openers like "I think..." (McManus \& Aiken 1996) or they feel that sentence openers excessively restrict their communication (Lazonder et al. 2003). For these reasons, more attention should be paid to framing appropriate conditions and suitable tasks in using chat for effective argumentation.

In the present study the sentence openers used were based on regular argumentative strategies. Their purpose was to structure interaction and to stimulate argumentative discussion between students. 


\section{Theoretical approaches to the visualisation of information}

Keller et al. (2006) have justified the benefits of visualisation with reference to three cognitive theories: the theory of computational efficiency (Larkin \& Simon 1987), the cognitive theory of multimedia learning (Mayer 2001), and the cognitive load theory (Sweller et al. 1998). The computational efficiency theory (Larkin \& Simon 1987) includes the idea that different representations with the same content (e.g. textual and diagrammatic representations) can enable different reasoning processes. Textual representations, i.e. successive words, are sequential, whereas diagrammatic representations are indexed by their location in a plane. This allows learners to see possible links between relevant units of information at adjacent locations.

According to the cognitive theory of multimedia learning (Mayer 2001), a combination of text and graphics leads to better retention of information than the use of only one representational form. This is possible because utilising the capacity of two information processing systems (verbal and visual) the cognitive resources needed for information processing are distributed between both systems. This also allows more information to be processed than if only one system is used. In addition, information visualisations can prevent cognitive overload (cognitive load theory; Sweller et al. 1998) because they enable an individual to focus on information that is directly relevant to the given topic. Combining a visualising task with an argumentation task may, by contrast, also evoke cognitive load since argumentation is a demanding activity requiring high-level interaction (e.g. Kuhn \& Udell 2003).

\section{Visualisation of argumentation by diagrams}

Diagrams have often been used as a means to visualise argumentation. Argument diagrams have been shown to improve university students' critical thinking (Twardy 
2004) and their understanding of argumentative relations (Suthers 2003). In the study conducted by Schwarz et al. (2000), fifth grade students expressed better arguments when they jointly constructed an argument diagram on vivisection compared to students who just jointly listed arguments for and against it. Furthermore, argument diagrams have been found to help both university students (van Boxtel \& Veerman 2001) and secondary school students (van Drie et al. 2005) to express arguments for and against in a balanced way.

When argument diagrams are constructed on the basis of a preceding chat debate, students encounter two forms of knowledge representation (chat and a diagram). Chat debate is a written text which proceeds linearly and vertically. When the argumentative structure of a linear chat debate is visualised in a diagram, knowledge takes a form of horizontal and spatial representation. In this way visualisation reveals the non-linear nature of the argumentation of a chat debate (see van Amelsvoort et al. 2008).

Argument diagrams can also be thought to give affordances (see e.g. Jermann 2004) to students in the learning situation. First, a diagram can help students not only to gain a grip on argumentation as a whole but can also direct and shape their reasoning. Students can then see links between different arguments, deepen their argumentation within a particular line of argument or add new arguments to the diagram from other viewpoints. In addition, not only the links within one chain of argument but also the interlinks between different chains of arguments are valuable for learning (van Amelsvoort et al. 2008).

The between-structure (interlinks) of argumentation should help students to weigh up the relations between different viewpoints and the arguments expressing them. However, although this kind of elaboration of arguments is important for learning, it seems to be difficult for students to master. Van Amelsvoort et al. $(2007 ; 2008)$ found 
that interlinks which indicate the between-structure of argumentation were rare in students' diagrams; the latter tended simply to resemble linear narrative text.

In this study the students' task was to recapitulate the argumentative content of their previous chat debate and to further develop their argumentation on the topic by constructing or modifying an argument diagram. The research questions posed in this study were as follows:

1) How much breadth, balance, and depth of argumentation, and what level of counterargumentation were incorporated in the free and modified argument diagrams, respectively, constructed by students on the basis of their previous chat debates?

2) How did the students develop their argumentation from their preceding debates in their free and modified diagrams?

3) What were the students' opinions on the usefulness of the different chat (free and structured) and argument diagram tools (freely constructed and modified)?

\section{Method}

\section{Teaching experiment}

The study was carried out in a Finnish secondary school as a part of a course in mother tongue. Sixteen students (aged between 16 and 17 years) participated in the course. Before the teaching experiment the students had been taught the main principles of argumentation and the main features of the computer software they would be using.

The students were divided into two groups. The experiment was carried out in two sessions on different days using two conditions and two topics (Table 1). In the first session (90 minutes) the discussion topic was vivisection and in the second session (90 
min) gender equality. During the first session group 1 worked under condition A (free chat) and group 2 under condition B (structured chat). During the second session the order was reversed.

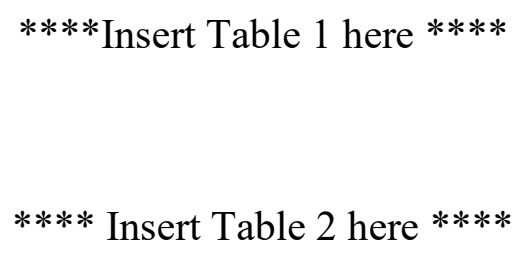

The teaching experiment consisted of five phases (Table 2). During the introduction phase (35/20 minutes) the students were taught how to use the free and structured chat tools. In order to trigger students' motivation for the subsequent chat discussions the students' prior knowledge of vivisection was activated by a cloze task and their knowledge of gender equality through a discussion.

During the preparation phase (20 minutes) the students read three articles containing arguments both for and against the topic. While reading, the students were asked to think about the different viewpoints on the topic presented in the texts and arguments to support them.

During the debate phase (15 min) the students engaged in chat discussions in pairs in both conditions. The teacher formed the student pairs as to maximise the number of mixed gender pairs. She also paired students whom she knew would work well together. The students were asked to discuss the following topic-related claims: "Vivisection should be allowed / There is gender equality in Finland". Under condition A the students used free chat and under condition B they used structured chat.

After the debates the students in both conditions were asked to construct an argument diagram (20 minutes) together with their partner on the basis of their debate. 
In condition A the students constructed a joint diagram freely using the diagram tool. They were asked in their diagram to include the most central claims, arguments, and counterarguments that emerged during their debate. They were also asked to add new arguments and counterarguments to the diagram. In condition B the students modified a diagram the computer had already made during the debate. Their task was to check that the argument diagram was meaningful in content and to modify it if necessary. The pairs were able to reduce and complete arguments, remove redundant boxes and check whether the links between arguments (“+” signs for supported and "_" signs for refuted arguments) were correct. They were also asked to add new arguments that they had not expressed during their debate. In both conditions the students were also encouraged to elaborate their arguments by adding commentary boxes behind argument boxes and writing comments in them.

At the end of the $2^{\text {nd }}$ session the students answered a short feedback questionnaire on the teaching experiment concerning the usefulness of the chat and argument diagram tools. The questionnaire contained six Likert-scale items, five on argument diagrams, and one open-ended question asking the students for opinions on pros and cons of constructing argument diagrams.

\section{Technological tools used during the experiment}

The chat debates were carried out using both free and structured chat tools. The free chat tool was an ordinary synchronous textual chat integrated into an Internet-based learning environment (DREW, Dialogical Reasoning Educational Webtool; see Corbel et al. 2002). The structured chat tool (ALEX, Argumentative Learning Experience; Hirsch et al. 2004) consisted of four categorised sets of either full or partial sentences. The sets were: 1) Argument, 2) Explore, 3) Opinion, and 4) Comment (see Table 3). 
Each set consisted of templates that students could either select or complete. The partial sentences inside the argument and explore sets are based on regular patterns of argumentative strategies, and contain a reference to one or more previous sentences (Hirsch et al. 2004).

\footnotetext{
**** Insert Table 3 here ****
}

The argument diagrams were constructed by both a free and an automatic diagram tool. The free diagram tool enabled students to write arguments in boxes, to draw links between the boxes, and to label the links as either supportive $(+)$ or critical $(-)$ (see Clark et al. in press). The automatic tool built a diagram in parallel with the structured chat discussion on the basis of the templates in the argument and explore sets. The free argument diagram tool was interconnected with the free chat tool, and the automatic diagram construction tool with the structured chat tool.

\section{Data}

The data consist of 16 dyadic chat debates (609 speech turns in total) and 16 argument diagrams (205 argument boxes in total; Table 4). Eight debates were carried out by free chat, and eight by structured chat. Eight collaborative diagrams were constructed freely, while the other eight diagrams were modified after the automatic tool had constructed them. The data also include 16 feedback questionnaires. 


\section{Data analyses}

Argumentative structure in the diagrams

The diagrams were analysed, first, by differentiating the claims, arguments, counterarguments and refutations of counterarguments, and their interrelations (see Björk \& Räisänen 1996). Second, the breadth, balance and depth of argumentation (Lund et al. 2007) and counter-argumentativeness of the diagrams were defined. Breadth of argumentation was measured by counting the number of arguments and counterarguments directly linked to the main thesis. For example, a score of 5 was given for Breadth in the diagram in Figure 1. Balance of argumentation was assessed by counting the difference $(|\mathrm{x}|)$ between the number of arguments for and against the main thesis: The higher the value, the lower the balance ( 0 indicates full balance). For example, in Figure 1 Balance is scored 1.0. Depth of argumentation was defined by counting the mean length of the argument chains included in the diagram. The length of a chain of arguments was based on the number of arguments and counterarguments successively linked to each other. For example, Depth of argumentation in the diagram in Figure 1 is 2.6 (mean length of the five argument chains). The Counterargumentativeness of the diagrams was calculated by dividing the total number of counterarguments and refutations of counterarguments by the total number of claims and arguments: the higher the value, the higher the counter-argumentativeness. If the number of arguments and counterarguments is the same, the score for counterargumentativeness is one, as is the case in Figure 1. 
Origin, transfer and elaboration of ideas

The origin and transfer and elaboration of the ideas presented in the constructed and modified argument diagrams were analysed in order to examine how the students further developed their argumentation following the chat debate (Marttunen \& Laurinen 2007). The origin of the ideas was classified into three categories: 1) the students' preceding dyadic chat debate, 2) the texts the students had read before their debate, and 3) students' general prior knowledge. The transfer and elaboration of ideas was classified into four categories (the unit of analysis was an argument box):

1) Copied, i.e. arguments which students copied directly from the related chat debates to their diagrams.

2) Slightly modified, so that modifications retained the meaning of the original arguments. The students, for example, removed extra words, such as "for example" from their previous arguments, or corrected spelling mistakes.

3) Revised. Modifications in which students revised a previous argument by recapitulating, rewording, or replacing part of it, or elaborating it in some way. For example, one dyad recapitulated the argument "Animals do have a sense of feeling, don't they? Well then, they feel pain like humans" expressed in the chat debate to the words "Animals have a sense of feeling".

4) Added a new argument, i.e. new argument boxes added to the diagram. These arguments were not presented during the chat debates. By means of these modifications the students enlarged the range of their argumentation on the topic.

Furthermore, in the case of modified diagrams 1) the visual modifications in the layout of arguments were noted and 2) the number of deletions in the existing argument boxes was counted. 


\section{Statistical analyses}

The diagrams were classified into four groups according to their form (free, modified) and the discussion topic (vivisection, gender equality). Nonparametric Kruskal-Wallis variance analysis $\left(X^{2}\right)$ was used to test for differences between the different groups of diagrams. The two-by-two comparisons of the diagrams were performed by the MannWhitney test $(U)$.

\section{Results}

\section{Structure of argumentation in the diagrams}

When the extent to which the topic was explored in the diagrams was observed, it was found that the dyads either supported or directly criticised the main thesis with, on average, 3.6 arguments (Breadth; Table 5). Although the variation in the means of the different types of diagrams was fairly high - from 2.3 in the modified diagrams on vivisection to 5.0 in the free diagrams on gender equality - the diagrams did not differ statistically significantly from each other $\left(\chi^{2}=4.48 ; d f=3 ; p=.215\right)$. The diagrams were to some extent unbalanced (total mean of Balance of argumentation, $M=1.3$ ). The differences between the different types of diagrams were not statistically significant $\left(\chi^{2}\right.$ $=2.16 ; d f=3 ; p=.539)$. Moreover, the students further elaborated their lines of reasoning relating to arguments for and counterarguments against the main thesis. The argument chains (Depth) ranged in length from 2.2 to 4.4 with a mean of 2.9. The different types of diagrams did not differ from each other $\left(\chi^{2}=5.79 ; d f=3 ; p=.122\right)$.

Almost all the claims and arguments in the diagram had been rebutted by a counterargument (Counter-argumentativeness, $M=0.8$ ). The differences between the diagrams were statistically significant $\left(\chi^{2}=8.32 ; d f=3 ; p=.040\right)$. The two-by-two comparisons showed that the modified diagrams on vivisection were on average more 
counterargumentative than the modified diagrams on gender equality (Means 1.3 and $0.4 ; U=0.00 ; p=.029)$.

\author{
**** Insert Table 5 here $* * * *$
}

\title{
Origin of ideas
}

When the origin of the ideas presented in the diagrams was tracked, it was found that $59.1 \%$ of the content of the free diagrams and $90.1 \%$ of the content of the modified diagrams originated from the related chat debates. In the free diagrams $30.3 \%$ of the content was associated with the texts the students had read before their dyadic discussion, and $10.7 \%$ was based on the students' prior knowledge (associated neither with the chat debates nor with the texts). In he modified diagrams $7.3 \%$ of the content was based on students' prior knowledge and $2.7 \%$ on the texts.

For example, in the diagram in Figure 1 eight boxes are based on the students' previous chat debate, four boxes (light grey) are associated with the texts, and the content of one (white) box is based on prior knowledge.

\section{Transfer and elaboration of arguments}

The students' most common way of constructing arguments in the diagrams was to revise the contents of the arguments presented in their previous chat debates $(39.5 \%$, see Table 6). The second most common way was to add a new argument to the diagram (29.3\%) and the third most common way was to copy the content of argument boxes directly from the related chat debates $(26.3 \%)$.

In the free diagrams the revising of existing arguments (44.4\%) and adding a new argument (44.4\%) were both common ways of further developing argumentation. In the modified diagrams, in turn, the students most often either left intact the arguments 
automatically copied by the computer $(50.5 \%)$ or revised them $(34.0 \%)$. The proportion of new arguments was $12.8 \%$.

**** Insert Table 6 here $* * * *$

Visual modification of automatically constructed diagrams

When examining more closely how the students modified the diagrams it was noticed, first, that they rearranged the arguments the computer had presented vertically and in a chronological order. Second, the students separated the argument boxes from each other so that the different argument chains could be seen more easily. Third, they deleted redundant, non-argumentative and request boxes $(M=4.5 ; S D=3.3)$.

Figure 2 illustrates an automatically constructed argument diagram on gender equality based on a structured chat debate and Figure 3 shows how the students have modified it. Comparison of these two diagrams shows that the students have rearranged the vertical and chronological structure of argumentation (Fig. 2) into a more illustrative form (Fig. 3). The students have also separated the argument boxes from each other so that the different chains of arguments can be seen more easily. Furthermore, they have deleted one explorative argument box (8 in Fig. 2) and two boxes ( 2 and 10 in Fig. 2) which were request templates. Finally, the students have added two new boxes based on the texts and constructed a new higher level argument box ("teachers have different gender expectations") so that they have moved one already existing argument (11 in Fig. 2) into a commentary box. This change, where a distinction is made between a general level argument and an example justifying it, indicates higher order thinking. In the same way the students have distinguished an argument from the example by dividing one argument box (number 12 in Fig. 12) into an argument and an example 
(box 12 and comment in it in Fig. 3). In addition, the students have added two new comments: one exemplification (box 9 in Fig. 3) and one caveat note (box 7 in Fig. 3).

\author{
$* * * *$ Insert Figure 2 here $* * * *$ \\ **** Insert Figure 3 here $* * * *$
}

\title{
Students' feedback on usefulness of the different chat and argument diagram tools
}

Half of the students ( 8 of 16) found it easier to chat freely than face-to-face, and 7 students found the reverse. Most of the students did not like the idea of choosing their speech turns from ready-made templates (13 of 16). They also found it difficult to find a suitable response option (12/16). Furthermore, a majority (14/16) of the students would have wanted the structured chat tool to include more response templates. Most of the students also reported that they often chose the same templates $(10 / 16)$. The same number of students, however, reported that it was easy to refer to statements with the help of numbers.

A majority of the students found it easy to construct (12/16) or to modify $(11 / 16)$ the argument diagrams. More than one-half of the students (10/16) reported that constructing argument diagrams helped them to understand the topic of the debate from more diverse viewpoints. Accordingly, many students (11/16) reported that it was useful to construct argument diagrams when learning argumentation skills. Furthermore, nearly all the students (14/16) felt that argument diagrams helped them to understand the structure of an argumentative debate.

The students mentioned that constructing argument diagrams has the following advantages: it clarifies their thinking (6/16), it is useful and interesting (5/16), it helps 
one to structure and sum up the debate (4/16), and facilitates understanding of how an argument proceeds $(3 / 16)$. Half of the students $(8 / 16)$, however, found constructing the diagram difficult and also somewhat boring and time-consuming.

\section{Discussion}

In this study the students constructed argument diagrams on the basis of free chat debates or they modified automatically constructed diagrams on the basis of structured chat debates. The different types of diagrams did not differ from each other in terms of breadth, depth, and balance of argumentation. In addition, all the diagrams contained mostly counter-argumentation $(M=0.8)$. The resemblance of the different types of diagrams (free vs. modified) indicates that students themselves are able to analyse the salient argumentative content of their debate and thereby capture its argumentative structure.

Almost a third $(30.3 \%)$ of the content of the free diagrams was based on the texts the students had read beforehand, whereas the respective proportion in the modified diagrams was only $2.7 \%$. Thus, free construction of diagrams seems to activate students to integrate what they have read previously into their co-constructed diagrams (see also Marttunen \& Laurinen 2007). This is in line with Mayer's (2001) statement that a combination of text and graphics supports learning.

In constructing and modifying their diagrams the students mostly presented their arguments in the same order as they were presented in their debates. This result is in accordance with the finding that students usually take a narrative approach in designing argument diagrams (van Amelsvoort et al. 2007). Further, the students focused mainly on the content of the boxes and less on interlinks between the argument boxes in different argument chains. When modifying automatically constructed diagrams the 
students had to work on the linear structure of the argumentation process to make sense of it. They broke up the chronological order of the arguments presented during their debates and rearranged the arguments into separate chains. To encourage students to pay more attention to the interlinks between argument chains in their diagrams, they could be asked to pay more attention to the visual organisation of arguments by clustering boxes on the same topic together, or by locating positive and negative arguments on different sides of the diagram (van Amelsvoort 2006; van Amelsvoort et al. 2008).

The purpose of combining two modes of representations (chat and diagram) in practising argumentation was to prompt students to integrate both their previous ideas and ideas presented in the texts they had read with the arguments put forward during the chat debates. The combining of ideas obtained from different sources has been shown to promote text comprehension (King 2007; Stahl et al. 1996). In this study the combining of different text sources, chat and previously read texts, promoted students' deeper understanding of the discussion topics.

It was assumed at the outset of the experiment that the automatically constructed diagrams would reduce students' cognitive load and thus enable them to focus more on their previous knowledge; however, this was not the case. In fact, the freely constructed diagrams contained more previous knowledge $(41 \%=30.3 \%$ from the texts and $10.7 \%$ from the students' existing knowledge) than the modified diagrams $(10 \%=7.3 \%+$ $2.7 \%$ respectively). Making diagrams by writing text into empty boxes that are easy to move and link with other boxes seems to support knowledge construction. In this study the automatic construction of argument diagrams did not help the students in their knowledge work. In learning contexts it is extremely important that technical tools are not allowed to do cognitive work on behalf of students. Even the attempt to decrease the 
cognitive load on students by transferring their ideas mechanically from structured chat debates to argument diagrams did not help them to develop their ideas further. Whether the use of templates and sentence openers designed to help students to concentrate solely on the argumentative content of texts fosters learning when practising argumentation remains a topic for further studies.

The results of the study indicated that when modifying an automatically constructed diagram the students concentrated mostly on checking that the diagram was meaningful in content. This result suggests that revising automatically constructed diagrams was an insufficient task to evoke students' higher order thinking. It seems that students should have a more specific purpose for reformulating diagrams such as utilising the revised diagram in a writing task. Another way to utilise the computer's automatic construction of argument diagrams is to ask students to look at the diagrams simultaneously when they are discussing. This might support their reasoning processes. For example, students can focus on the differences in their opinions and elaborate their arguments by giving examples either to justify or criticise them. This may also broaden and deepen their discussion and foster co-construction of knowledge. The study by Munneke et al. (2003) showed that students discussed differences in their opinions and broadened the space of their debate more often when inspecting than when constructing diagrams.

Collaborative creation of new argument diagrams and revision of already existing diagrams seem to provide opportunities to students for both learning to argue and arguing to learn. When creating new diagrams on the basis of previous discussions, students have to analyse their discussions in order to find out the salient arguments and visualise them. These activities favour students' co-elaboration of knowledge (arguing to learn). When revising existing diagrams, students have to examine the structure of 
their argumentation and they should be explicitly prompted to elaborate their reasoning further, for example, by giving examples to justify their arguments (learning to argue). Thus, both creation and revision of argument diagrams can be regarded as useful means to support students' learning.

\section{References}

Baker M. (2003) Computer-mediated argumentative interactions for the co-elaboration of scientific notions. In Arguing to learn. Confronting cognitions in computersupported collaborative learning environments (eds J. Andriessen, M. Baker \& D. Suthers), pp. 47-78. Kluwer, Dordrecht.

Baker M. \& Lund, K. (1997) Promoting reflective interactions in a computer-supported collaborative learning environment. Journal of Computer Assisted Learning 13, $175-193$.

Björk L. \& Räisänen C. (1996) Academic writing. A university writing course. Studentlitteratur, Lund.

Burnett C. (2003) Learning to chat: tutor participation in synchronous online chat. Teaching in Higher Education 8 (2), 247-261.

Chan C.K.K. (2001) Peer collaboration and discourse patterns in learning from incompatible information. Instructional Science 29, 443-479.

Clark D., Sampson V., Stegmann K., Marttunen M., Kollar I., Janssen J., Weinberger A., Menekse M., Erkens G. \& Laurinen L. (In press) Online learning environments, scientific argumentation and 21 st century skills. To in $E$ Collaborative knowledge construction: Learning from computer-supported and virtual environments. IGI Global. 
Condon S.L. \& Cech C.G. (1996) Functional comparison of face-to-face and computermediated decision making interactions. In Computer Mediated Communication: linguistic, social and cross-cultural perspectives (ed. S.C. Herring), pp. 65-80. Benjamins, Amsterdam.

Corbel A., Girardot J. \& Jaillon P. (2002) DREW: a dialogical reasoning web tool. In Educational technology: Vol 1. Proceedings of the international conference on ICT's in education (ICTE 2002) (eds A. Mendes Villas, J.A. Mesa Gonzalez \& I. Solo de Zaldivar), pp. 516-521. Junta de Extremadura, Consejeria de education, cienca y technologia, Badajoz, Spain.

Erkens G. (1997) Coöperatief probleem oplossen met computers in het onderwijs : het modelleren van coöperative dialogen voor de ontwikkeling van intelligente onderwijssystemen [cooperative problem solving with computers in education : modeling of cooperative dialogues for the design of intelligent educational systems]. Unpublished doctoral dissertation. Utrecht University, The Netherlands.

Erkens G. (2004) Dynamics of coordination in collaboration. In Dialogic learning. Shifting perspectives to learning, instruction and teaching (eds J. van der Linden \& P. Renshaw), pp. 191-216. Kluwer, Dordrecht.

Farnham S., Chesley H.R., McGhee D.E., Kawal R. \& Landau J. (2000) Structured online interactions: improving the decision-making of small discussion groups. Proceedings of the 2000 ACM conference on Computer Supported Cooperative Work, Philadelphia, Pennsylvania, United States, pp. 299-308.

Hirsch L., Saeedi M., Cornillon J. \& Litosseliti L. (2004) A structured dialogue tool for argumentative learning. Journal of Computer Assisted Learning 20 (1), 72-80. 
Hron A., Hesse F., Cress U. \& Giovis C. (2000) Implicit and explicit dialogue structuring in virtual learning groups. British Journal of Educational Psychology 70, 53-64.

Jermann P. (2004) Computer support for interaction regulation in collaborative problem-solving. Doctoral dissertation. University of Geneva, Switzerland.

Keller T., Gerjets P., Scheiter K. \& Garsoffky B. (2006) Information visualizations for knowledge acquisition: The impact of dimensionality and colour coding. Computers in Human Behavior 22 (1), 43-65.

King A. (2007) Beyond literal comprehension: a strategy to promote deep understanding of text. In Reading comprehension strategies. Theories, interventions, and technologies (ed. D.S. McNamara), pp. 267-290. Erlbaum, New York.

Kuhn D., Shawn V. \& Felton M. (1997) Effects of dyadic interaction on argumentative reasoning. Cognition and instruction 15, 287-315.

Kuhn D. \& Udell W. (2003) The development of argument skills. Child Development 74, 1245-1260.

Larkin J.H. \& Simon H.A. (1987) Why a diagram is (sometimes) worth ten thousand words. Cognitive Science 11, 65-99.

Lazonder A.W., Wilhelm P. \& Ootes S.A.W. (2003) Using sentence openers to foster student interaction in computer-mediated learning environments. Computers and Education 41, 291-308.

Litosseliti L., Marttunen M., Laurinen L. \& Salminen T. (2005) Computer-based and face-to-face collaborative argumentation in secondary schools in England and Finland. Education, Communication, and Information 5 (2), 131-146. 
Lund K., Molinari G., Séjourné A. \& Baker M. (2007) How do argumentation diagrams compare when student pairs use them as a means for debate or as a tool for representing debate? International Journal of Computer-Supported Collaborative Learning 2, 273-295.

Marttunen M. (1997) Studying argumentation in higher education by electronic mail. Jyväskylä Studies in Education, Psychology and Social Research 127. University of Jyväskylä, Jyväskylä.

Marttunen M. \& Laurinen L. (2007) Collaborative learning through chat discussions and argument diagrams in secondary school. Journal of Research on Technology in Education 40 (1), 109-126.

Marttunen M., Laurinen L., Litosseliti L. \& Lund K. (2005) Argumentation skills as prerequisites for collaborative learning among Finnish, French, and English secondary school students. Educational Research and Evaluation 11 (4), August $2005,365-384$.

Mayer R.E. (2001) Multimedia learning. Cambridge University Press, Cambridge, MA. McAlister S. (2004) Dialectics and design for online peer discussion. Unpublished $\mathrm{PhD}$ thesis, Institute of Educational Technology, Open University, UK.

McManus M.M. \& Aiken R.M. (1996) Teaching collaborative skills with a group leader tutor. Education and Information Technologies 1, 75-96.

Mercer N. (1996) The quality of talk in children's collaborative activity in the classroom. Learning and Instruction 6 (4), 359-377.

Morgan W. \& Beaumont G. (2003) A dialogic approach to argumentation: Using a chat room to develop early adolescent students' argumentative writing. Journal of Adolescent \& Adult Literacy 47 (2), 146-157. 
Munneke L., van Amelsvoort M. \& Andriessen, J. (2003) The role of diagrams in collaborative argumentation-based learning. International Journal of Educational Research 39, 113-131.

Reznitskaya A., Anderson A., McNurlen B., Nguyen-Jahiel K., Archodidou A. \& Kim S. (2001) Influence of oral discussion on written argument. Discourse Processes 32 (2), 155-175.

Robertson J., Good J. \& Pain H. (1998) BetterBlether: the design and evaluation of a discussion tool for education. International Journal of Artificial Intelligence in Education 9, 219-236.

Stahl S.A., Hynd C.R., Britton B.K., McNish M.M. \& Bosquet D. (1996) What happens when students read multiple source documents in history? Reading Research Quarterly 31 (4), 430-456.

Suthers D. (2003) Representational guidance for collaborative inquiry. In Arguing to learn. Confronting cognitions in computer-supported collaborative learning environments (eds J. Andriessen, M. Baker \& D. Suthers), pp. 27-46. Kluwer, Dordrecht.

Schwarz B., Neuman Y., Gil J. \& Ilia M. (2000) Construction of collective and individual knowledge in argumentative activity: an experimental study. The Journal of the Learning Sciences 12, 219-256.

Sweller J., van Merriënboer J. \& Paas F. (1998) Cognitive architecture and instructional design. Educational Psychology Review 10, 251-296.

Twardy C.R. (2004) Argument maps improve critical thinking. Teaching Philosophy 27 (2), 95-116. 
Van Amelsvoort M. (2006) A space for debate. How diagrams support collaborative argumentation-based learning. Doctoral dissertation. ICO, Dutch Interuniversity Center for Educational Research. PrintPartners Ipskamp, Enschede.

Van Amelsvoort M., Andriessen J. \& Kanselaar G. (2008) How students structure and relate argumentative knowledge when learning together with diagrams. Computers in Human Behavior 24, 1293-1313.

Van Amelsvoort M., Andriessen J. \& Kanselaar G. (2007) Representational tools in computer-supported collaborative argumentation-based learning: how dyads work with constructed and inspected argumentative diagrams. The Journal of the Learning Sciences 16 (4), 485-521.

Van Boxtel C. \& Veerman A. (2001) Diagram-mediated collaborative learning. Diagrams as tools to provoke and support elaboration and argumentation. In European perspectives on computer-supported collaborative learning. Proceedings of the First European conference on computer-supported collaborative learning (eds P. Dillenbourg, A. Eurelings \& K. Hakkarainen), pp. 131-138. Universiteit Maastricht, the Netherlands.

Van Drie J., van Boxtel C., Jaspers J. \& Kanselaar G. (2005) Effects of representational guidance on domain specific reasoning in CSCL. Computers in Human Behavior 21, 575-602.

Van Gelder T. (2003) Enhancing deliberation through computer supported argument visualization. In Visualizing argumentation. Software tools for collaborative educational sense-making (eds P.A. Kirschner, S.J. Buckingham Shum \& C.S. Carr), pp. 97-115. Springer, London.

Veerman A. (2000) Computer-supported collaborative learning through argumentation. Unpublished doctoral dissertation. Utrecht University, The Netherlands. 
Weger H. \& Aakhus M. (2003) Arguing in internet chat rooms: argumentative adaptations to chat room design and some consequences for public deliberation at a distance. Argumentation and Advocacy 40, 23-38. 
Table 1. Design of the study

\begin{tabular}{|c|c|c|}
\hline \multirow{2}{*}{ GROUP } & \multicolumn{2}{|c|}{ SESSION } \\
\cline { 2 - 3 } & $\mathbf{1}^{\text {st }}$ Session, Day 1 (90 min) & $\mathbf{2}^{\text {nd }}$ Session, Day 2 (90 min) \\
\hline \multirow{2}{*}{ Group 1 } & $\begin{array}{c}\text { Vivisection } \\
\text { (Condition A }\end{array}$ & $\begin{array}{c}\text { Gender equality } \\
\text { (Condition B) }\end{array}$ \\
\hline \multirow{2}{*}{ Group 2 } & $\begin{array}{c}\text { Vivisection } \\
\text { (Condition B) }\end{array}$ & $\begin{array}{c}\text { Gender equality } \\
\text { (Condition A) }\end{array}$ \\
\hline
\end{tabular}


Table 2. Phases of the teaching experiment

\begin{tabular}{|c|c|c|c|}
\hline \multirow{2}{*}{\multicolumn{2}{|c|}{ PHASE }} & \multicolumn{2}{|c|}{ CONDITION } \\
\hline & & \multicolumn{2}{|c|}{ Both conditions (A \& B) } \\
\hline \multirow{2}{*}{ Introduction } & $\begin{array}{l}1^{\text {st }} \text { session } \\
(35 \mathrm{~min})\end{array}$ & \multicolumn{2}{|c|}{$\begin{array}{l}\text { Training with the chat tools ( } 25 \mathrm{~min}) \text {, and a cloze test on vivisection ( } 10 \\
\text { min). }\end{array}$} \\
\hline & $\begin{array}{l}2^{\text {nd }} \text { session } \\
(20 \mathrm{~min})\end{array}$ & \multicolumn{2}{|c|}{ General discussion on gender equality. } \\
\hline \multicolumn{2}{|c|}{ Preparation $(20 \mathrm{~min})$} & \multicolumn{2}{|c|}{ Reading three articles on the topic in each session. } \\
\hline \multirow{2}{*}{\multicolumn{2}{|c|}{ Debate $(15 \mathrm{~min})$}} & Condition A & Condition B \\
\hline & & Free chat. & Structured chat. \\
\hline \multicolumn{2}{|c|}{$\begin{array}{l}\text { Diagram construction } \\
(20 \mathrm{~min})\end{array}$} & $\begin{array}{l}\text { Free construction of an } \\
\text { argument diagram. }\end{array}$ & $\begin{array}{l}\text { Modifying a diagram constructed by } \\
\text { the computer. }\end{array}$ \\
\hline \multicolumn{2}{|c|}{$\begin{array}{l}\text { Feedback questionnaire } \\
(15 \mathrm{~min})\end{array}$} & \multicolumn{2}{|c|}{ Feedback questionnaire on the experiment at the end of the $2^{\text {nd }}$ session. } \\
\hline
\end{tabular}


Table 3. Templates of the structured chat

\begin{tabular}{|c|c|c|}
\hline \multicolumn{2}{|c|}{$\begin{array}{l}\text { CATEGORISED SETS } \\
\text { OF TEMPLATES }\end{array}$} & TEMPLATES \\
\hline \multirow{2}{*}{ 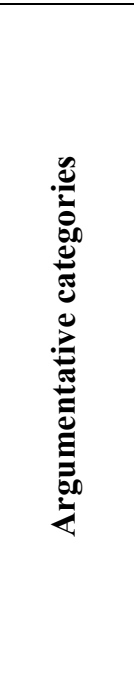 } & Argument & $\begin{array}{l}\text { 1) Can you give an argument for statement } \mathrm{X} \text { ? } \\
\text { 2) I support statement } \mathrm{X} \text { because several Finnish women have gone a long } \\
\text { way in our country. } \\
\text { 3) Can you give an argument against statement X? } \\
\text { 4) I attack statement X because men are not yet equally making their way into } \\
\text { "female domains". }\end{array}$ \\
\hline & Explore & $\begin{array}{l}\text { 5) Can you clarify statement X? } \\
\text { 6) I would like to clarify statement X by saying that in general gender } \\
\text { equality is a fact. } \\
\text { 7) There is a problem between statement X and statement } \mathrm{Y} \text { because men have } \\
\text { full freedom enter to "female domains". } \\
\text { 8) I retract statement X because the attitudes of society and of my friends } \\
\text { greatly affect in the situation. } \\
\text { 9) Can you give an example to justify statement X? } \\
\text { 10) I would like to justify statement X by saying that in our school there is a } \\
\text { nameless male teacher of maths who cannot understand that girls can be } \\
\text { good in maths as well. }\end{array}$ \\
\hline \multirow{2}{*}{ Z } & Opinion & $\begin{array}{l}\text { 11) I don't agree with statement } X \text {. } \\
\text { 12) I agree with statement } X \text {. } \\
\text { 13) I changed my opinion about statement } X \text {. } \\
\text { 14) What is your opinion about statement } X \text { ? }\end{array}$ \\
\hline & Comment & $\begin{array}{ll}\text { 15) Hello! } & \text { 19) Hurry up! } \\
\text { 16) Bye! } & \text { 20) Slow down! } \\
\text { 17) My turn. } & \text { 21) I would like to talk about statement X. } \\
\text { 18) Your turn. } & \text { 22) I see what you mean. }\end{array}$ \\
\hline
\end{tabular}

Note: $\mathrm{X}=$ number of speech turn; examples of how the students used the templates in debating the topic gender equality are given in italics. 
Table 4. Data of the study

\begin{tabular}{|c|c|c|c|c|c|}
\hline \multirow{2}{*}{$\begin{array}{c}\text { Mode of } \\
\text { chat }\end{array}$} & Topic & Chat debates & Speech turns & Diagrams & $\begin{array}{c}\text { Argument } \\
\text { boxes }\end{array}$ \\
\cline { 3 - 6 } & & $\boldsymbol{f}$ & $\boldsymbol{f}$ & $\boldsymbol{f}$ & $\boldsymbol{f}$ \\
\hline \multirow{2}{*}{ Free } & Vivisection & 4 & 188 & 4 & 53 \\
\cline { 2 - 6 } & Gender equality & 4 & 232 & 4 & 55 \\
\hline \multirow{2}{*}{ Structured } & Vivisection & 4 & 94 & 4 & 38 \\
\cline { 2 - 6 } & Gender equality & 4 & 95 & 4 & 59 \\
\hline Total & & 16 & 609 & 16 & 205 \\
\hline
\end{tabular}




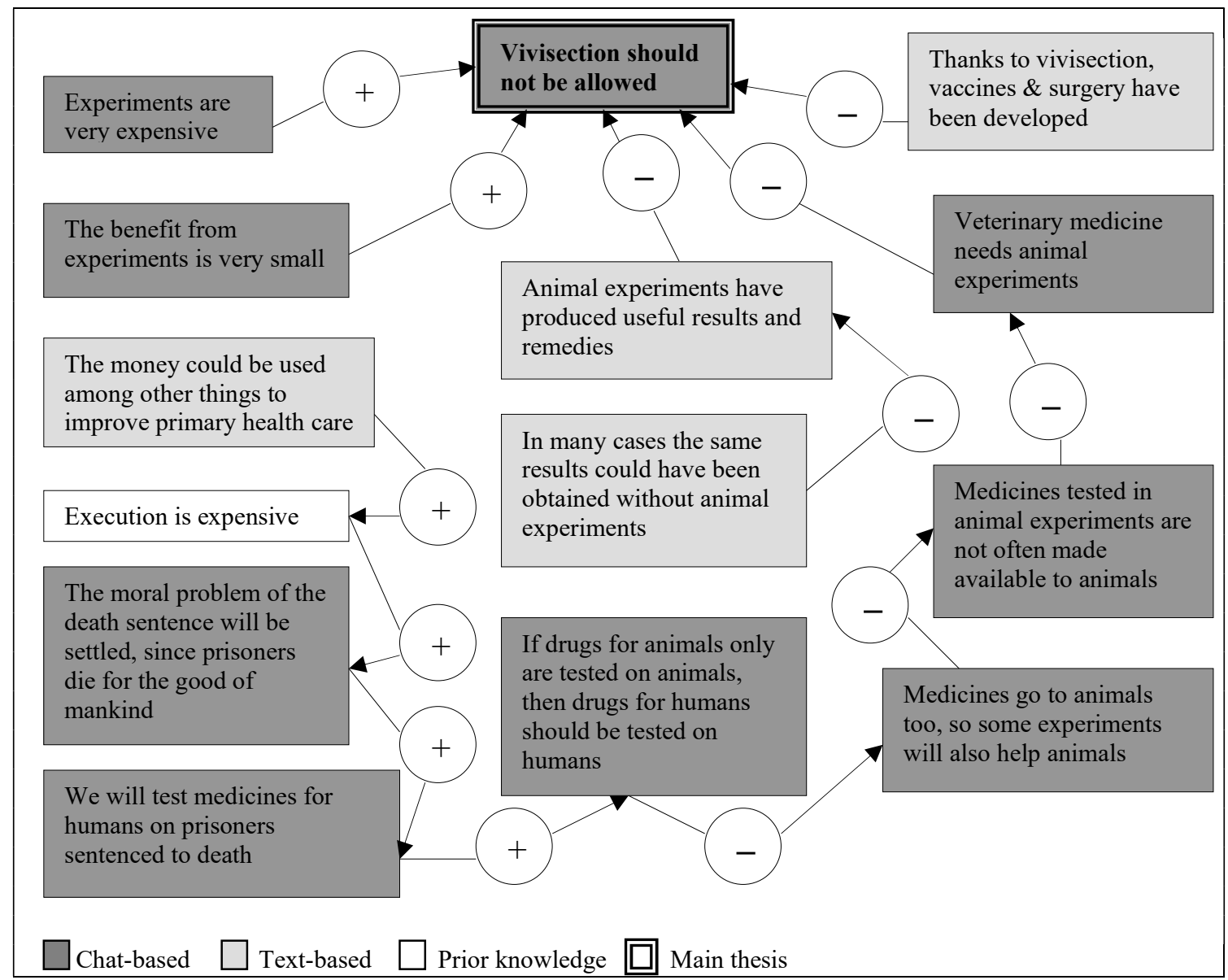

Figure 1. An argument diagram on vivisection based on free chat debate 
Table 5. Means and standard deviations of parameters of argument diagrams in four groups

\begin{tabular}{|c|c|c|c|c|c|c|c|c|c|}
\hline \multirow[b]{3}{*}{ Type of diagram } & & \multicolumn{8}{|c|}{ Structure of argumentation } \\
\hline & & \multicolumn{2}{|c|}{ Breadth } & \multicolumn{2}{|c|}{ Balance } & \multicolumn{2}{|c|}{ Depth } & \multicolumn{2}{|c|}{$\begin{array}{c}\text { Counter- } \\
\text { argumentativeness }\end{array}$} \\
\hline & $n$ & $M$ & $S D$ & $M$ & $S D$ & $M$ & $S D$ & $M$ & $S D$ \\
\hline $\begin{array}{l}\text { Free diagrams on } \\
\text { vivisection }\end{array}$ & 4 & 3.5 & 1.9 & 1.0 & 0.0 & 2.3 & 0.8 & 0.5 & 0.4 \\
\hline $\begin{array}{l}\text { Modified diagrams } \\
\text { on vivisection }\end{array}$ & 4 & 2.3 & 1.3 & 0.8 & 1.0 & 4.4 & 1.7 & 1.3 & 0.4 \\
\hline $\begin{array}{l}\text { Free diagrams on } \\
\text { gender equality }\end{array}$ & 4 & 5.0 & 2.2 & 2.0 & 1.4 & 2.2 & 0.6 & 0.8 & 0.3 \\
\hline $\begin{array}{l}\text { Modified diagrams } \\
\text { on gender equality }\end{array}$ & 4 & 3.5 & 1.3 & 1.5 & 1.7 & 2.5 & 0.7 & 0.4 & 0.3 \\
\hline Total & 16 & 3.6 & 1.8 & 1.3 & 1.2 & 2.9 & 1.3 & 0.8 & 0.5 \\
\hline
\end{tabular}


Table 6. Transfer and elaboration of arguments

\begin{tabular}{|c|c|c|c|c|c|c|}
\hline \multirow{2}{*}{$\begin{array}{c}\text { Category of } \\
\text { arguments }\end{array}$} & \multicolumn{2}{|c|}{ Free diagrams } & \multicolumn{2}{c|}{ Modified diagrams } & \multicolumn{2}{c|}{ Total } \\
\cline { 2 - 7 } & $\boldsymbol{f}$ & $\mathbf{\%}$ & $\boldsymbol{f}$ & $\mathbf{\%}$ & $\boldsymbol{f}$ & $\mathbf{\%}$ \\
\hline Revised & 48 & 44.4 & 33 & 34.0 & 81 & 39.5 \\
\hline Added a new argument & 48 & 44.4 & 12 & 12.8 & 60 & 29.3 \\
\hline Copied & 5 & 4.6 & 49 & 50.5 & 54 & 26.3 \\
\hline Slightly modified & 7 & 6.9 & 3 & 3.1 & 10 & 4.9 \\
\hline Total & 108 & 100 & 97 & 100 & 205 & 100 \\
\hline
\end{tabular}




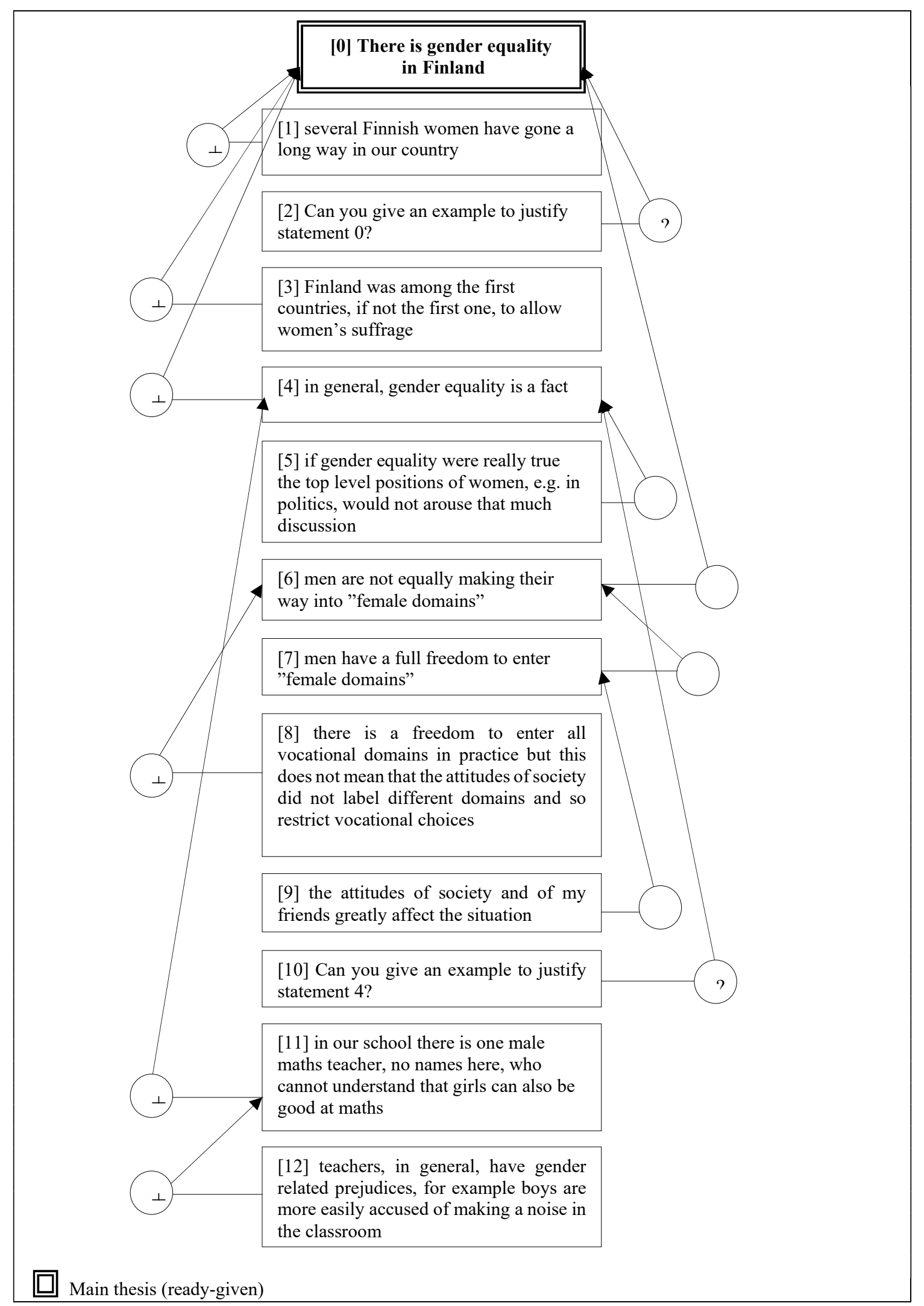

Figure 2. An automatically constructed argument diagram on gender equality based on structured chat debate 


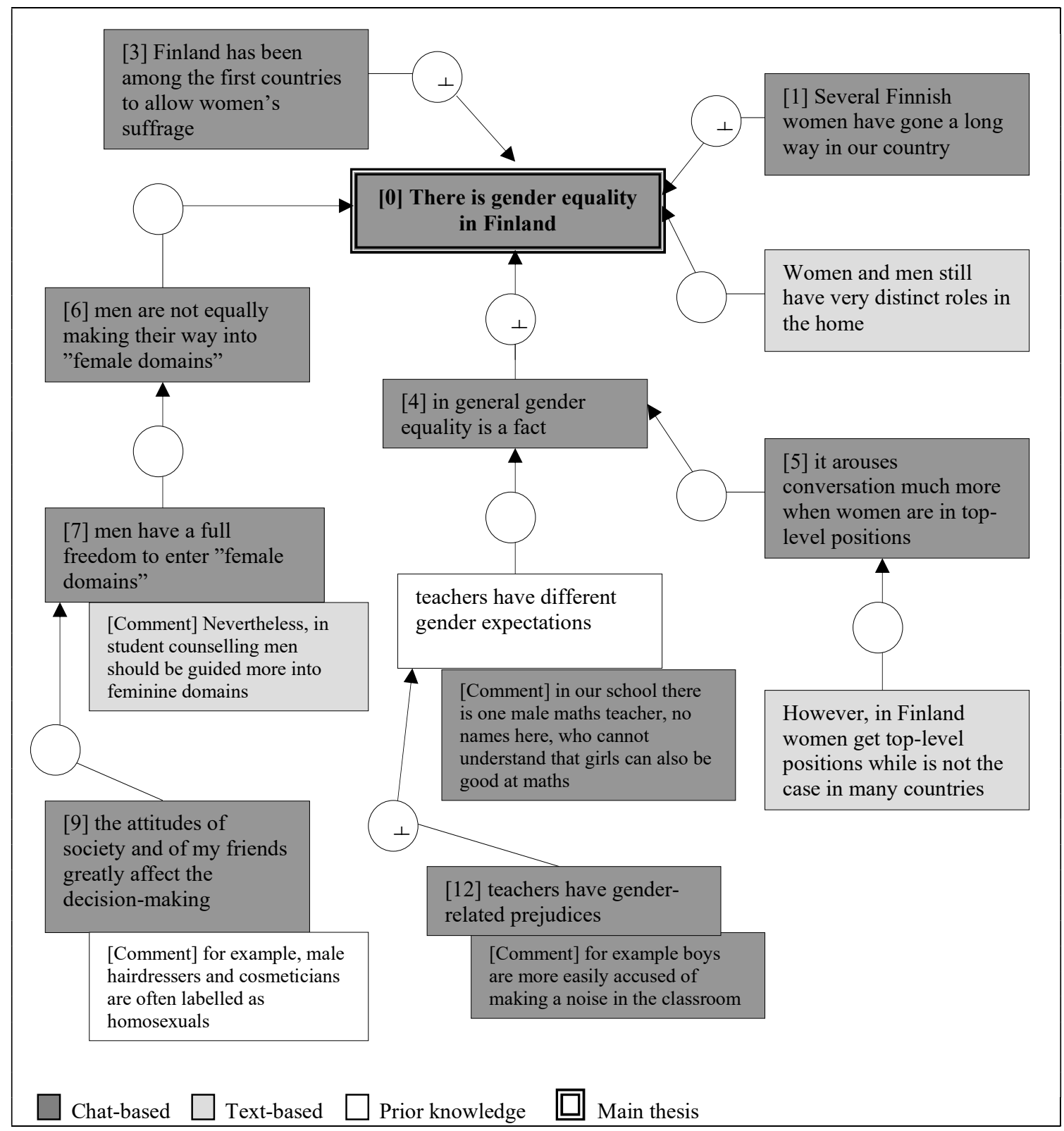

Figure 3. A modified argument diagram on gender equality based on structured chat debate. 